\title{
Neural Network Prediction of P-wave Log for Reservoir Characterization in the Niger Delta Basin
}

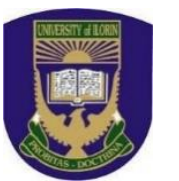

\author{
A. Ogbamikhumi*, S. A. Salami, W. N. Uwadiae \\ Department of Geology, University of Benin, Benin, Nigeria.
}

ABSTRACT: This study present a new technique that integrates several logs for P-wave prediction to minimize some errors and uncertainties associated with most estimation methods. The adopted method involves application of an artificial neural network technique that integrates density, resistivity and gamma ray logs for data training and the prediction of $\mathrm{P}$-wave log. The results obtained gave correlation coefficient of $0.77,0.24$ and 0.42 between the acquired $\mathrm{P}$-wave $\log$ and the acquired density, resistivity and gamma ray logs respectively, to demonstrate the relationship between $\mathrm{P}$-wave $\log$ and the selected logs for the prediction process. The correlation coefficient of the estimated Pwave from Gardner and Faust methods with the acquired P-wave log are 0.64 and 0.59 respectively, while that of the neural network derived P-wave gave a better correlation coefficient of 0.81 . Cross plot validation of P-wave derive Acoustic Impedance against density for both lithology and fluid discrimination revealed clusters for neural network derived P-wave parameter similar to the acquired P-wave derived parameters. Results of the presented neural network technique have been demonstrated to be more effective than results of the two conventional techniques.

KEYWORDS: Sonic log, Gardner's method, Faust method, Neural network, Cross plot.

[Received February 7, 2019, Revised September 19, 2019, Accepted October 29, 2019] Print ISSN: 0189-9546 | Online ISSN: 2437-2110

\section{INTRODUCTION}

In most hydrocarbon fields, It is pretty the case for some $\log$ records to be absent as a result of failure of instrument, incomplete logging, bad hole conditions, damaged instruments, data loss due to unsuitable storage or some logs may not be acquired at all due to cost (Schon, 2015). In any of such cases, it is important to devise means of estimating some vital logs where absent. P-wave or Sonic log is one of such vital well $\operatorname{logs}$ that are frequently absent in some fields. Hence, several means have been adopted for its prediction; among these methods are the Faust (Faust, 1951) and Gardner (Gardner et al., 1974) approximation, which depends on only Resistivity log and Density log respectively for its prediction. These methods of $\mathrm{P}$-wave estimation are somewhat useful, but they are accompanied with significant errors and uncertainties. Hence the need to present a more accurate method of predicting sonic log with less associated errors.

More recently, Artificial Neural Network (ANN) models, which has an outstanding ability to define a complex mapping between non-linearly related input and output data have been increasingly adopted effectively to predict reservoir properties from wells and seismic. And also, modelling of complex systems (Li, 1994;Mohaghegh et al., 1996; Al-Bulushi et al., 2009; Aminim and Ameri, 2005; Chakraborty, 2010).

In this study, three basic well logs (Gamma ray, Density, and resistivity $\operatorname{logs}$ ) would be integrated using a supervised neural network technique; Probability Neural Network (PNN) to train the logs and ultimately, predict sonic $\log$. The results will eventually be compared with estimation from the conventional methods and the acquired sonic log from the studied field, to evaluate its effectiveness.

*Corresponding author: alexander.ogbamikhumi@uniben.edu
The study field (Nowos Field) is one of the hydrocarbon fields in the Niger Delta Basin, and the basin is located at the gulf of Guinea in West Africa. It is one of the most prolific hydrocarbon bearing deltas in the world. The field lies between latitude $8020^{\prime} 00^{\prime}$ ' $\mathrm{N}$ and $8050^{\prime} 00^{\prime} \mathrm{N}$ and Longitude $6030^{\prime}$ $00^{\prime \prime}$ and $7010^{\prime} 00^{\prime \prime}$ and covers an area of $3610.656 \mathrm{~km} 2$ (Figure 1)

The overall basin is divided into different zones called depo-belts, due to its tectonic structure (Michele et al., 1999). These depo belts gets younger and more complex structurally from the continent down to the offshore Niger delta (Owejemi and Willis, 2006). Generally, five major depo-belts are structurally well-known. Each depo-belt has its own unique deformation, sedimentation and petroleum system. They are associated mainly with listric growth normal faults, collapse crest structure, rollover anticlines, diapiric structures e.t.c that serve as hydrocarbon trap mechanism. The study field is situated in the central swamp depo-belt. These depo-belt are described as an independent entities in terms of structural development, stratigraphy, and distribution of hydrocarbon (Unukogbon et al., 2008).

From the study of sedimentology, sequence stratigraphy, and the combined influence of eustatic cyclicity and local tectonics, three formations have been defined within the Niger Delta. These are from oldest to youngest namely; The pro-delta shale of the Akata, The intercalated shales and sands of the predominantly deltaic Agbada formation and the fluvial sands of the Benin formation (Short and Stauble, 1967; Doust and Omatsola, 1990; Owoyemi, 2006; Magbagbeoloa and Willis, 2007)

doi: http://dx.doi.org/10.4314/njtd.v17i1.4 


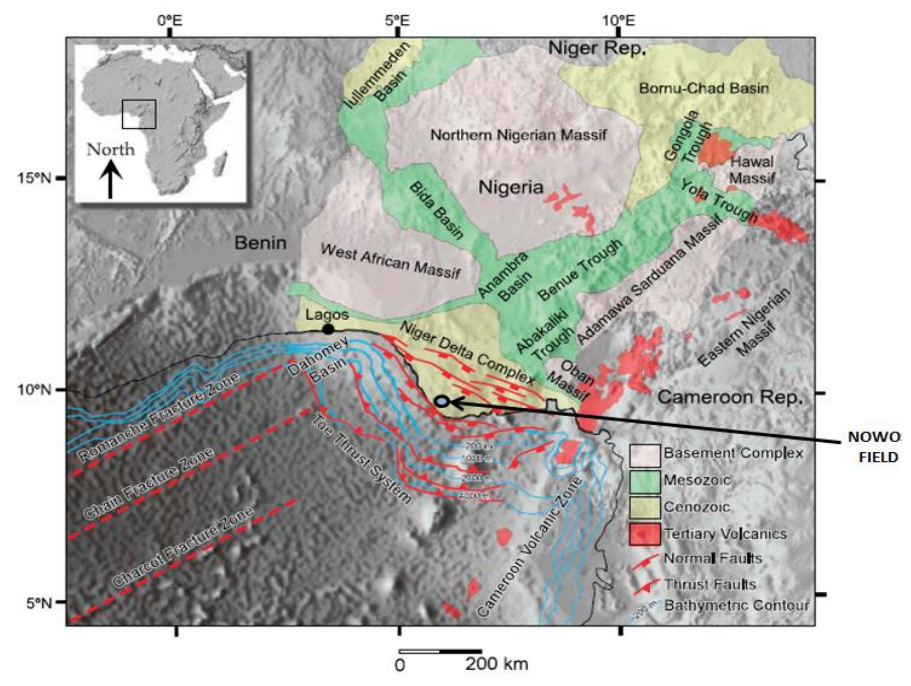

Figure 1: Map of Niger Delta showing the study area (Modified after Whiteman, 1982).

\section{MATERIALS AND METHODS}

Wells data obtained from Shell Petroleum Development Company (SPDC) were used for the study, and the three wells contain Gamma Ray logs, Resistivity logs, Sonic logs and Density logs. The Hampson Russell Suite HRS was the subsurface software employed for the study. Quality control checks that include de-spiking, filtering, data gaps, wash out and depth scaling were done after data loading.

The two commonly used techniques for sonic log prediction that include; Gardner and Faust methods as well as neural network algorithm were adopted to predict sonic log for correlation with the acquired sonic log. The three commonly available $\operatorname{logs}$ that includes the Gamma ray, resistivity and density logs were used for the training processes employing the PNN. A routine crossplot was later conducted to compare results of acquired sonic log derived parameter and the predicted sonic log derived parameter.

Faust method is a very old technique that uses Resistivity $\log$ to predict sonic log. The technique is depth dependent and it is more useful in shallow rock sequences, especially clastics. The method can be adopted where P-wave log is absent, and can be calibrated with offset well data, vertical seismic profiles or check shots. Unfortunately, the method does not account for gas effect. The equation that defines the Faust method is presented in eqn (1).

$$
\mathrm{Vp}=\mathrm{a} \times(\mathrm{d} \times \mathrm{R}) \mathrm{b}
$$

where; $\mathrm{Vp}=\mathrm{P}$-wave velocity in $\mathrm{ft} / \mathrm{s}$

$$
\begin{aligned}
& \mathrm{d}=\text { Depth in } \mathrm{ft} \\
& \mathrm{R}=\text { Resistivity in ohm- } \mathrm{ft}
\end{aligned}
$$

$\mathrm{a}$ and $\mathrm{b}$ are constant empirically derived constant 1948 and 0.166667 respectively.

The Gardner equation is an empirical equation that relates sonic velocity to bulk density. It is a pseudo-velocity relationship commonly used in estimating sonic or density logs when only one of them is available. The relationship is presented in eqn (2).

$$
\mathrm{p}=\alpha \mathrm{V}
$$

where $\mathrm{p}=$ bulk density

$\mathrm{Vp}=\mathrm{P}-\mathrm{Wave}$ velocity

$\alpha$ and $\beta$ are empirically derived constants that depend on geology.

Gardner et al., (1990) proposed that one can obtain a good estimate of density in $\mathrm{g} / \mathrm{cc}$, given velocity in $\mathrm{ft} / \mathrm{s}$, by taking $\alpha=0.23$ and $\beta=0.25$. The equation is very popular in hydrocarbon exploration because it can provide information about lithology from interval velocities obtained from logs or seismic.

For the neural network prediction of sonic log using the density $\log$, resistivity $\log$ and gamma ray $\log$ in the training process, the probability neural network was used. The PNN is a type of feed forward and supervised neural network that is widely used in classification and prediction problems. It is made up of several subclasses or sub-networks. In the Probabilistic neural network algorithm, the parent probability distribution function (PDF) of each class takes into consideration statistical parameters such as mean and variance for its approximation. (Li, 1994). Using PDF of each class, the PDF of a new set of input data is estimated and Bayes' rule is then applied to allocate the class with the highest posterior probability to new input data. By this technique, the probability of mis-classification and estimation is minimized.

\section{RESULTS AND DISCUSSION}

The results for $\mathrm{P}$-wave prediction using the conventional Gardner and Faust method that uses density and resistivity are displayed in tract 4 , along with the acquired sonic $\log$ of (Figure 2). The predicted sonic log from Gardner's method when cross plotted against the acquired log, gave a correlation coefficient of 0.64 (Figure 4), while the results of prediction done with the Faust method gave a correlation coefficient of 0.59 (Figure 3 ). With both correlation coefficient greater than 0.5 , they are good enough for some study that required sonic $\log$ when it is missing or when they are not acquired. The quality of such predicted logs could be unacceptable for the more sensitive quantitative interpretation and rock physics studies that requires very good quality logs.

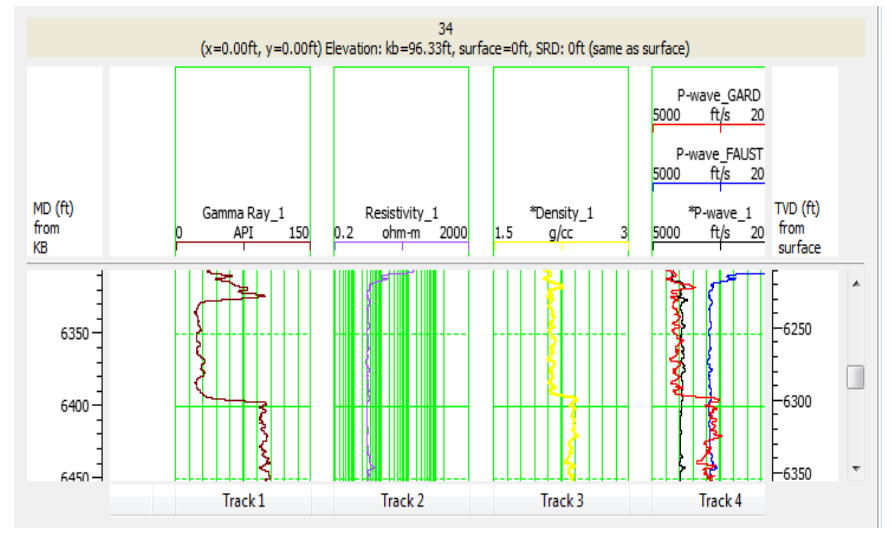

Figure 2: Log display of acquired P-Wave log (black curve), P-wave derived from Gardner (red curve) and Faust methods (blue curve) in tract 4. 


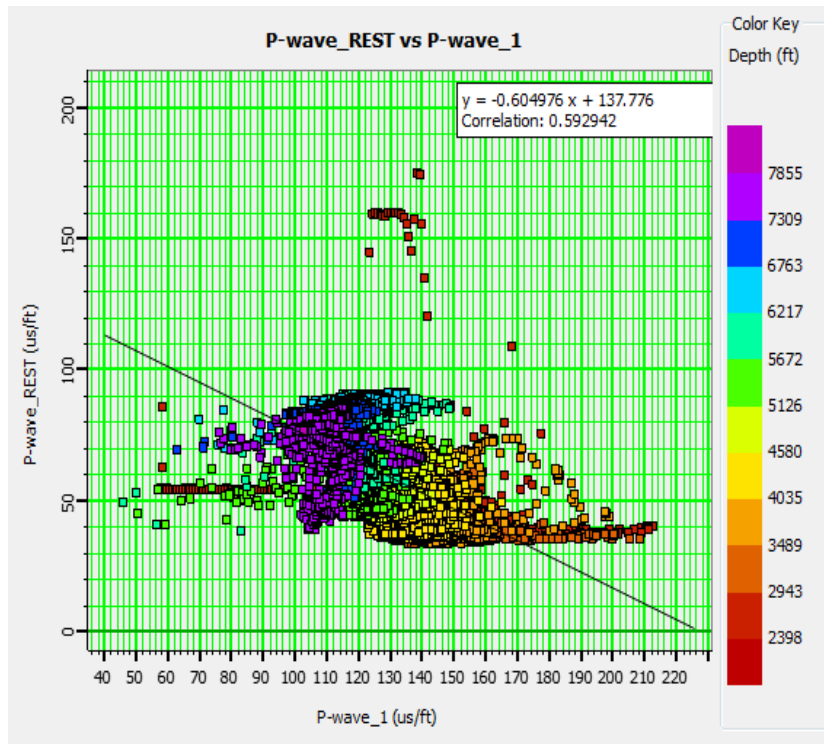

Figure 3. Cross Plot of Faust Method derived P-Wave against acquired P-wave.

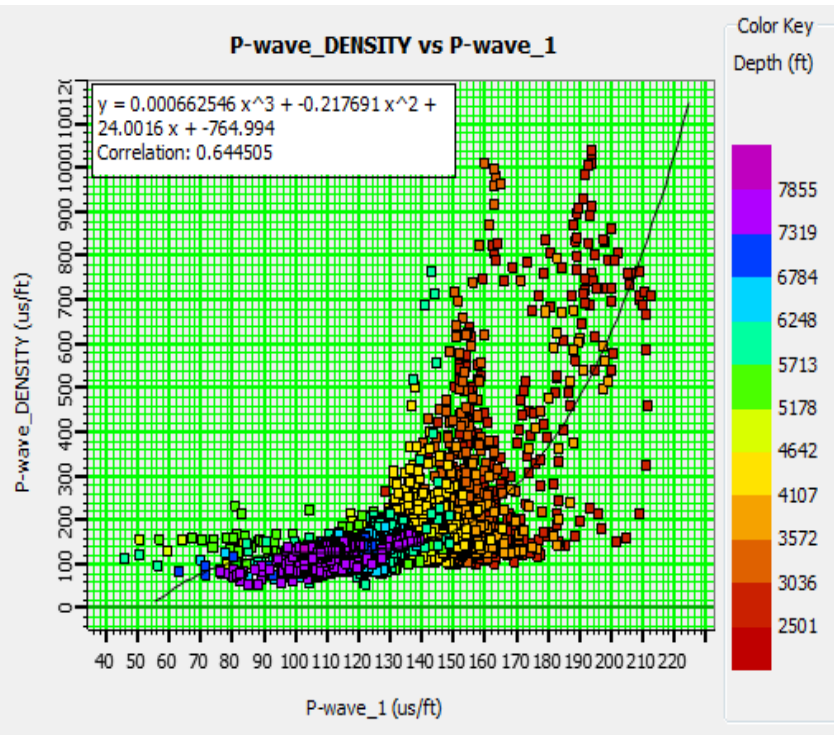

Figure 4. Cross Plot of Gardner Method derived P-Wave against acquired $P$-wave.

The results of sonic log prediction using Probability Neural Network algorithm with the three selected for the three available wells are displayed and superimpose on the acquired sonic log in Figure 5. The cross plot of acquired sonic log against the predicted $\log$ in Figure 6 gave an average correlation coefficient of 0.81 for the three wells. This correlation coefficient values is clearly higher than that obtained by both the Gardner and Faust methods of 0.64 and 0.59 respectively. Hence, this makes the technique obviously more suitable for sonic log prediction than the Gardner and Faust method when p-wave log is not acquired or missing.

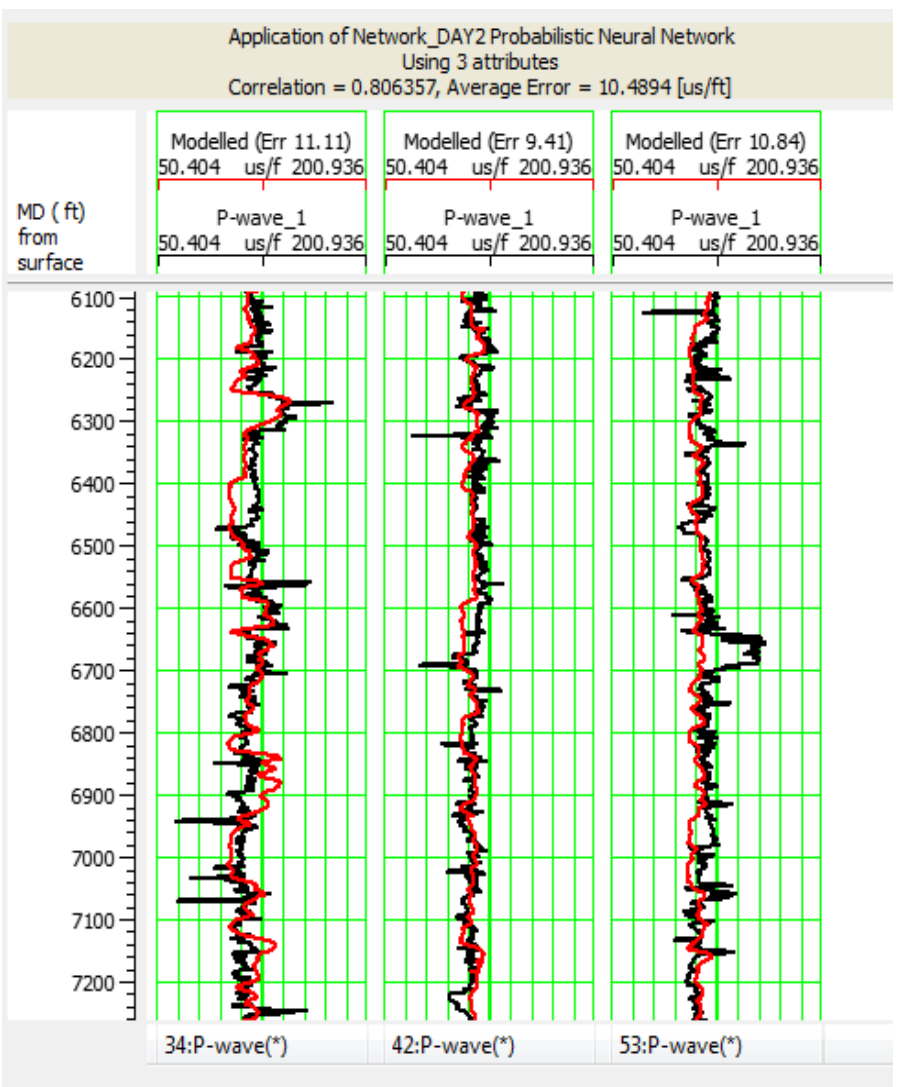

Figure 5: Correlation Panel of PNN-Pwave (Red curve) and Actual PWave (black Curve).

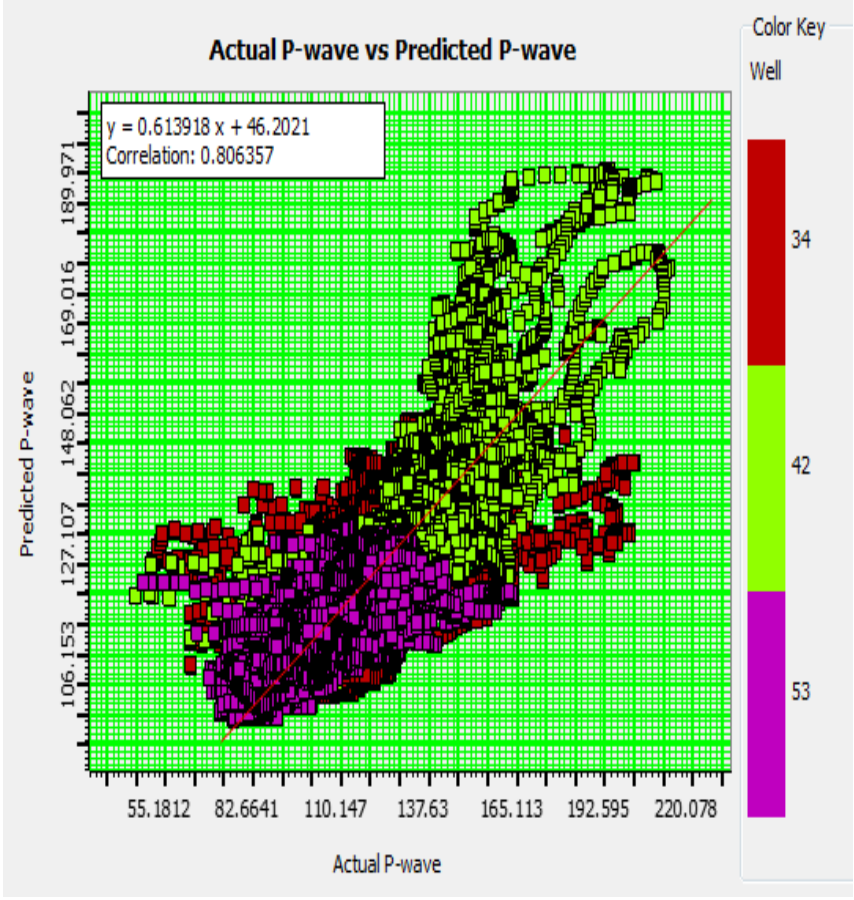

Figure 6: Cross Plot of Predicted P-Wave against Actual P-Wave. 
The log view in Figure 7 compares the predicted sonic log using the three methods with the acquired log. It was observed that the neural network predicted p-wave curve (Red curve or WISDOM_P_wave) has the closest behavior as the acquired pwave curve (Black curve).

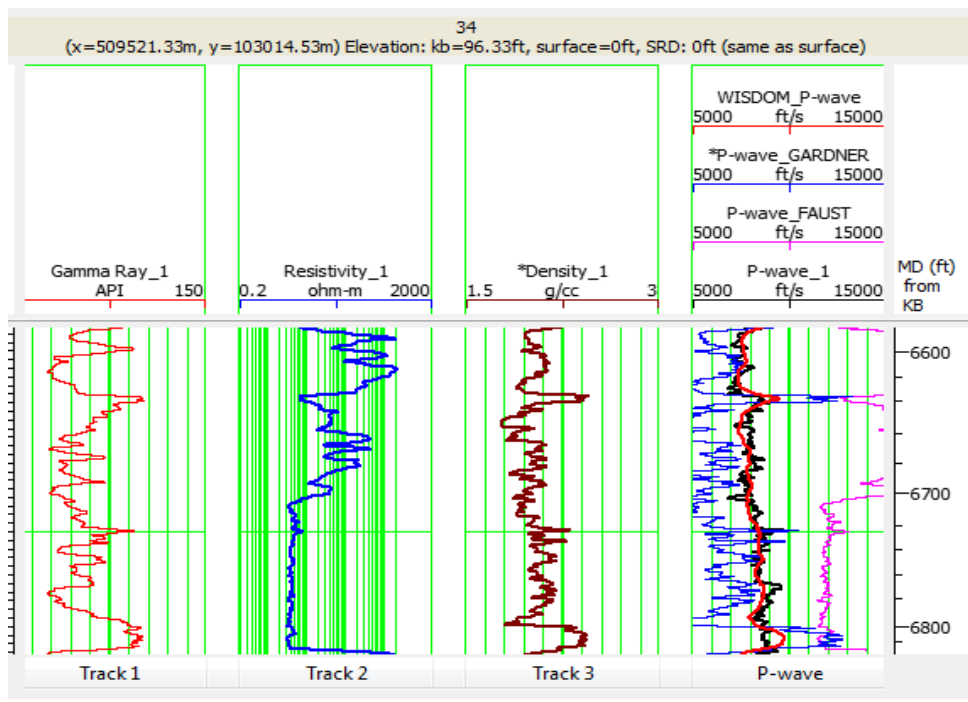

Figure 7: Display of the three different techniques

To demonstrated and validate the suitability of the three predicted sonic logs for rock physics studies, P-wave acoustic impedance curve was generated using the sonic log results from the prediction and the acquired sonic log. This derived parameter was cross plotted against density within a hydrocarbon bearing reservoir interval for both lithology and fluid discrimination.

Results for the cross plot of PNN P-wave derived parameters in Figure 9 clearly discriminate both lithology and fluid similar to that of the acquired P-wave derived parameters in Figure 8. In Figure 10, the cross plot conducted using the Faust method derived parameter reveal that the Acoustic impedance for the hydrocarbon bearing interval of the reservoir was over estimated (Red ellipse) compared to what was expected for the acquired parameter in Figure 8.

For Gardner derived sonic log, the cross plot in Figure 11, there was no identifiable cluster separation that can be attributed to lithology or fluid presence.
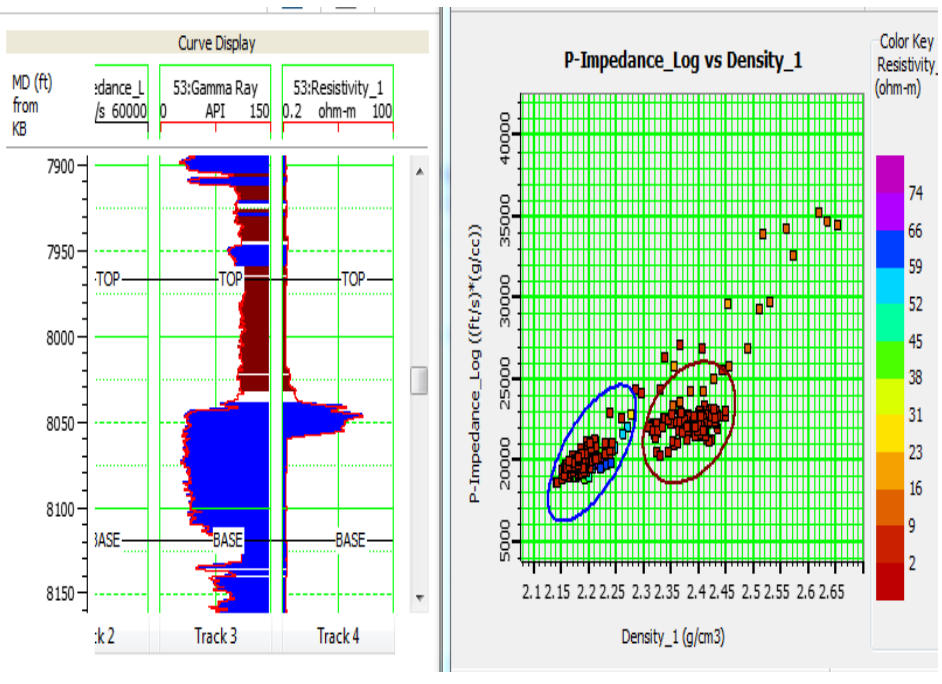

Figure 8: Log view and cross plot panel of acquired p-wave derived Acoustic Impedance against Density log.
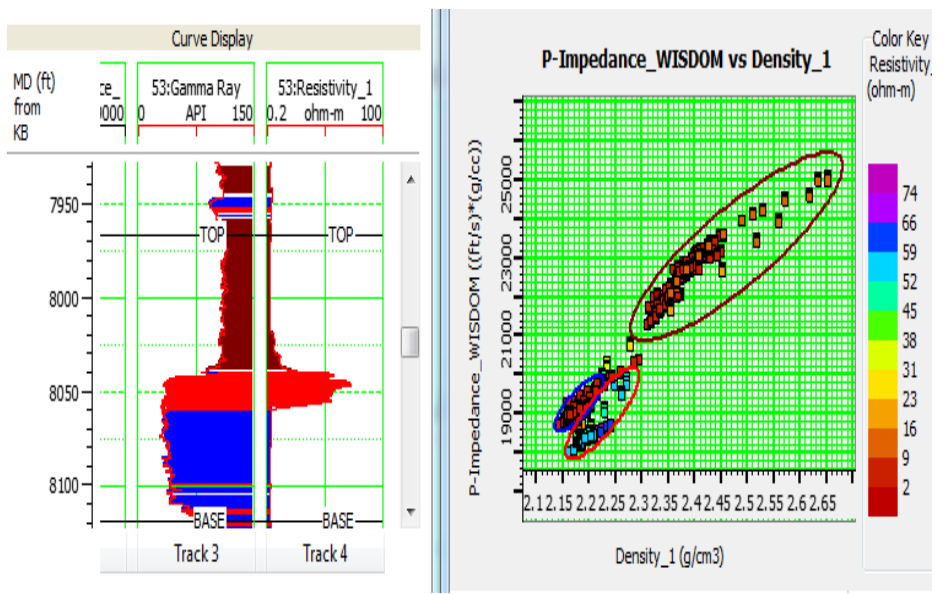

Figure 9: Log view and cross plot panel of PNN derived p-wave Acoustic Impedance against Density log.

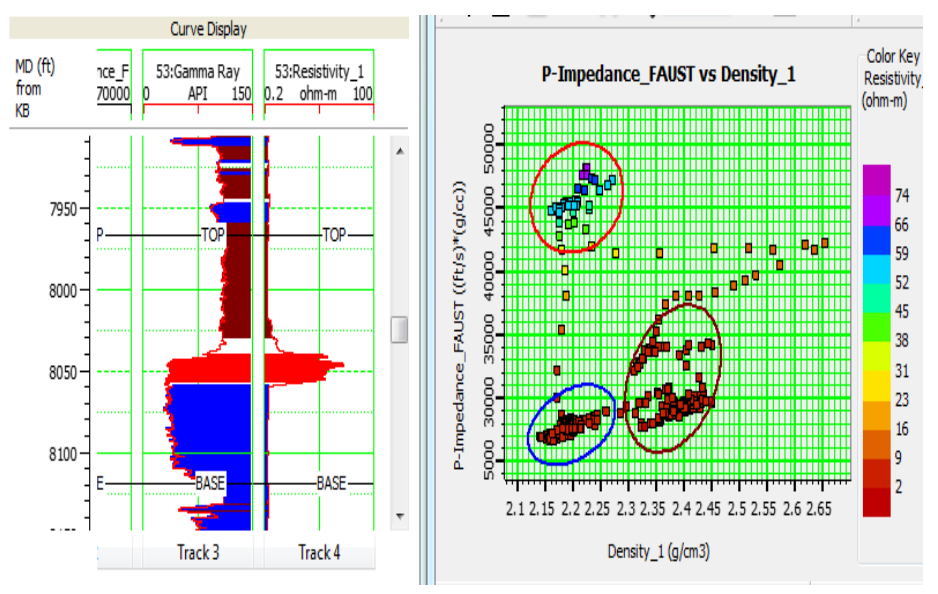

Figure 10: Log view and cross plot panel of Faust derived p-wave Acoustic Impedance against Density log. 


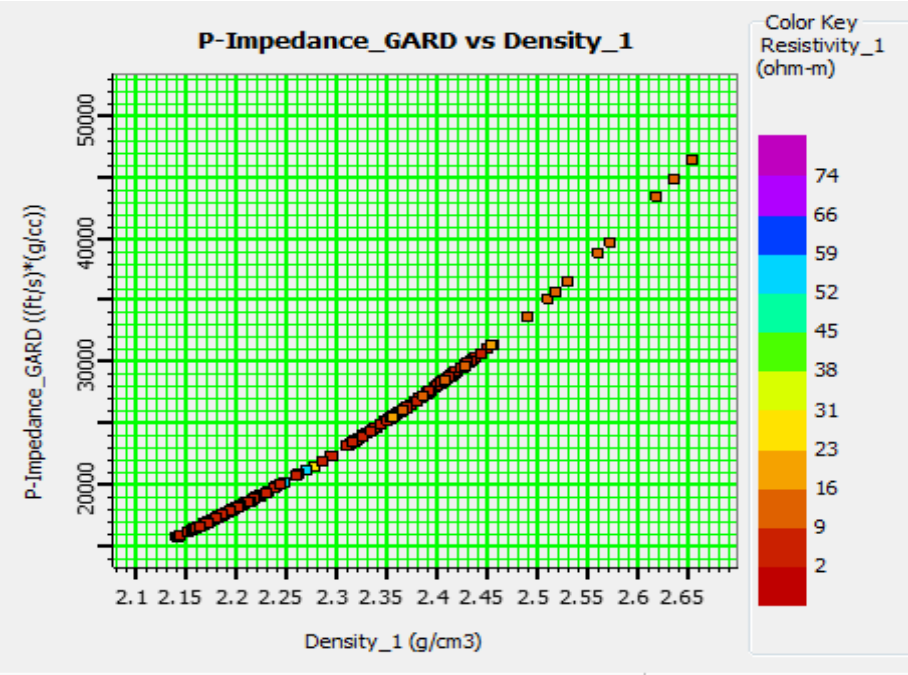

Figure 11: Log view and cross plot panel of Gardner method derived P-wave Acoustic Impedance against Density log.

\section{CONCLUSION}

The study presented a Probability Neural network as a new technique that can improve upon the conventional methods of sonic log prediction particularly more effective for rock physics and reservoir characterization. The network training process employs density log, resistivity log and gamma ray log for the training process to generate a transfer function for sonic log prediction.

The correlation coefficient of the PNN derived sonic log with the acquired sonic log gave a correlation coefficient of 0.8 , while the correlation coefficient of Gardner's and Faust's methods derived sonic logs with the acquired sonic log were 0.64 and 0.59 respectively.

Cross plot validation to test suitability of using the derived sonic log parameters from the three methods for reservoir characterization purpose revealed that the PNN derived P-wave parameter gave the closes cluster separations for both lithology and fluid discrimination as the acquired sonic log than those of Gardner and Faust derived P-wave parameter.

\section{REFERENCES}

Al-Bulushi, N.; P.R. King; M.J. Blunt and M. Kraaijveld. (2009). Development of artificial neural network models for predicting water saturation and fluid distribution. Journal of Petroleum Science and Engineering, 68 (3-4):197208.
Aminian, K. and Ameri, S. (2005). Application of artificial neural networks for reservoir characterization with limited data. Journal of Petroleum Science and Engineering, 49(3-4): 212-222.

Chakraborty, R. C. (2010). Fundamentals of Neural Networks: AI Course lecture notes, Arindam, California.

Doust, H. and Omatsola, E. (1990). Niger Delta, in J.D. Edwards and P.A. Santogrossi, eds., Divergent/Passive margin basins. American Association of Petroleum Geologists Memoir 48: $201-236$

Faust, L.Y. (1951). Seismic velocity as function of depth and geologic time. Geophysics, 16:192-206.

Gardner, J.W.; E.L. Hines and M. Wilkinson. (1990). Application of Artificial Neural Networks to an Electronic Olfactory System. Measurement Science and Technology, 1: 446-451.

Gardner, G.H.F.; L. W. Gardner and A.R. Gregory. (1974) Formation velocity and density - the diagnostic basics for stratigraphic traps: Geophysics, 39: 770-780.

Li, E. Y. (1994). Artificial neural networks and their business application. Information and Management, 27(5): 303-313.

Magbagbeoloa, $O$ and Willis, B.J. (2007). Sequence stratigraphy and syndepositional deformation of the Agbada Formation, Robertkiri field, Niger Delta, Nigeria. American Association of Petroleum Geologists Bulletin 91: 945-958

Michele L.W.T.; R.C. Ronald and E.B. Micheal (1999). The Niger Delta Petroleum System: Niger Delta Province, Nigeria, Cameroon and Equatorial Guinea. Africa. USGS open file report, 5

Mohaghegh S.; R. Arefi; S. Ameri; K. Aminian and R. Nutter. (1996). Petroleum reservoir characterization with the aid of artificial neural networks. Journal of Petroleum Science and Engineering, 16(4): 263-274.

Owoyemi, A.O. and Willis, B.J. (2006) Depositional patterns across syndepositional normal faults, Niger delta. Nigeria. Journal of Sedimentary Research 76: 346-363.

Schon, J.H. (2015). Physical Properties of rocks: Fundamentals and principles of petrophysics. Elsevier, 65.

Short K.C. and A.J. Stauble (1967). Outline of Geology of Niger Delta: American Association of Petroleum Geologist (AAPG) Bulletin, 51: 761-779.

Unukogbon, N. O.; G. O. Asuen and W. O. Emofurieta. (2008). Sequence stratigraphic appraisal: Coastal swamp depobelt in the Niger Delta Basin Nigeria. Global Journal of Geological Sciences, 6(2):129-137. 